\title{
Current Status and Perfection Measures of the Development of China's Green Logistics
}

\author{
Xianhui Duan \\ Nanchang Key Laboratory of material and structure detection Jiangxi University of Technology
}

Keywords: Logistics; Green logistics; Sustainable development; Policy

\begin{abstract}
Since $20^{\text {th }}$ century, the world economy has entered a rapid development stage, and logistics ind ustry has developed rapidly as well. However, since 1960s, the environmental problem brought by economic development has been increasingly severe. Hence, some experts and scholars begin to put forward "Protect Environment, Develop Low Carbon Economy", green logistics rises at the proper time. Green logistics still remains at the developing stage in China. This paper analyzes the urgency of China's development of green logistics, studies the current status of development of China's green logistics and obtains strategies which are suitable for China's development of green logistics by adopting SWOT analysis method and dissects various existing restraining factors in China's green logistics development. Based on the mode of development of foreign green logistics, it specifically proposes that China's development of green logistics has to emancipate though and establish new concept in developing green logistics.
\end{abstract}

\section{Research Objective and Significance of Current Status of Development of China's Green Logistics}

Firstly, green logistics has been adapted to the trend of development of the world's logistics industry. After joining WTO, China no longer restricts foreign logistics enterprises to enter Chinese market.

Secondly, green logistics is also a guarantee for logistics enterprises to gain core competitiveness. Thirdly, green logistics is also an essential guarantee for logistics to develop and grow stronger. To gain development, logistics has to cooperate with social sustainable development. Human's economic activities can't obsessively consume resources and destroy environment because of logistics, which will lead to repeated pollution. Therefore, choosing green logistics is inevitable in the development of logistics.

Fourthly, green logistics is the only way to best lower operating cost.

\section{Current Status of Development of Green Logistics}

European countries are one of the first countries to develop green logistics and began to explore a new affiliative or a new cooperative logistics system in 1980s, namely comprehensive logistics supply chain management, which aimed to implement logistics between the ultimate consumers and the original suppliers and the integration of logistics and information flow. Recently, it brought forward an integral transportation safety plan, which aimed to monitor vessel operation state. Organizations of transportation and logistics industry of European countries attach importance to 
promotion and development of green logistics and have formulated corresponding green standards in the process of transportation, handling and management, thus strengthening the government and enterprise association's role in guiding and planning green logistics and encouraging enterprises to apply brand new concept of green logistics to operate logistics activities. Current status of China's development of green logistics is as follows:

The concept of green logistics isn't yet popularized. Advancement and scientificity of concept of green logistics have been reflected more and more apparent on social and economic activities, and green logistics has been advocated by more and more people and enterprises. However, the concept of green logistics isn't yet popularized in China. People have weak awareness of green logistics and their understanding of the significance of green logistics isn't comprehensive enough.

Green logistics technology is relatively backward. The core content of green logistics does not only rely on people's emphasis and government policy and so on, but also depends on application and support of green logistics technology. Compared with foreign advanced logistics technology, China's logistics technological level remains certain gap. China's logistics has problems including disordered development, no good plan, insufficient degree of logistics mechanization and inconsistent of logistics appliance standards. Furthermore, logistics information management level and logistics technological means of Chinese enterprises are also relatively backward and lack of necessary public logistics information platform, which greatly and severely restricts the improvement of logistics operating efficiency and service quality.

Impe rfect national relevant policies. China has been committed to formulation of policies, laws and regulations related to environmental pollution since 1990s, but few frames aimed at establishment and development of green logistics and excessive department systems involved in logistics directly result in problems such as disordered development of logistics industry, severe waste of resources allocation and too many costs on operation link.

Backward research of green logistics and severe loss of talents. China's current research and educational level of logistics are pretty backward and there are few professional research institutions and professional university education, thus it is difficult to provide the development of China's logistics with powerful talent power. The development of green logistics is a systems engineering, whose complex and enormous work involves many professional fields. Whether it is macro logistics planning, logistics park management or logistics enterprise operation, they all should be supported by many professional logistics talents. Chinese colleges and universities pay little attention to this aspect, which fundamentally results in slow development of China's green logistics.

\section{SWOT Analysis of China's Development of Green Logistics}

Strength. Chinese government's emphasis on sustainable development: In China, sustainable growth of population and people's growing material and cultural needs are great pressure on economic construction and utilization of resources and environment. Hence, China's basic state policy is to adhere to sustainable development. Under the guidance of state policy, Chinese governments at all levels have brought forward many green engineering schemes and promoted enterprises' implementation of green management.

Environmental awareness of Chinese enterprises and the public have come into being. With the principles of national sustainable development, social responsibility awareness of many enterprises has been gradually formed, among which some enterprises have environmental protection awareness and regarded producing green products as competitive strength of enterprises. They have carried out 
cleaner production in accordance with environmental standards. For instance, Haier Group has already set up environmental management system and gained ISO14001 standard certification. It can be seen that green environmental protection awareness has been widely recognized by enterprises and the public.

China's modern logistics develops rapidly. In recent decades, China's modern logistics develops rapidly. China has introduced many advanced logistics technologies and management ideas, which has laid certain foundation for development of green logistics.

Weakness. The concept of green logistics is not yet popularized. Although environmental awareness increasingly wins support from the public, the concept of green logistics is not yet popularized in China. Many people even have no idea of what green logistics means.

The government is in lack of relevant policies guidance. A state's development of green logistics has to depend on strongly support from related governmental policies, e.g. green logistics law.

Being lack of logistics inter-disciplinary talents. China presented the concept of green logistics only a few years ago, its researches just start out. There are almost no graduates who have green logistics ideas cultivation. Meanwhile, research contents are lack of sufficient guiding significance in practice. Sometimes, theory has no connection to the actual cases.

Logistics technology is backward. Great disparity exists in China's logistics technology and green demand. Although some enterprises have already introduced advanced logistics technology, logistics information management level and technological means of most enterprises are relatively backward and are lack of necessary public logistics information and the service function is weak, which restricts the improvement of logistics operating efficiency and service quality, and it will surely cause waste of logistics resources.

Opportunity. China has a good integral economic environment. China's economy has presented good and continuous growth trend since the reform and opening up, which has offered a good environment for development of domestic green logistics.

The international main trend is to develop green logistics. Green logistics is adapted to the trend of the world's social development and is the need of global integration.

Joining WTO brings giant impetus to the development of China's green logistics.

Threat. Competitive threat from foreign logistics enterprises. After China joined WTO, foreign logistics enterprises with advanced operation management level, solid funds and advanced technical equipment enter Chinese market in succession, bring great impact on domestic logistics enterprises and even threaten the survival of domestic logistics enterprises.

Insufficient demand of green logistics market. Although Chinese logistics market has enormous potential, enterprises and the public have low demand for logistics environmental protection because the concept of green logistics is not yet popularized. Therefore, it also causes some enterprises which carry out green logistics to step back.

Intense fight over logistics talents.

\section{Perfection Measures of China's Green Logistics}

Governmental perfection policy and legal system. Laws and regulations concerning environmental protection is an important content among legal systems of various countries. However, regulations aimed at logistics activities haven't been made in environmental protection legal system. Hence, to advocate and develop green logistics, specialized laws and regulations formulated by the government are required. 
Enterprises accelerate the transition and carry out research of relevant technologies of green logistics. Vigorously develop and adopt green technology: Performance of green logistics mainly includes comprehensively developing green logistics technologies in logistics field, including standardized technology, information and communication technology, new material technology, biotechnology, environmental protection technology, safety defense technology, monitoring technology, preservation technology, various refuses disposal and recycling technology, special technology for various logistics functions, quality management and process reengineering, etc. Advanced green logistics technology is an important pillar of green logistics.

Strengthen construction of logistics information system and standardization system. Perfect logistics information system is an important foundation for developing green logistics and helps improve use ratio and economy of logistics resources. As for existing problems in China's current logistics standardization and development direction of international logistics standardization, the government should do basic work in aspects including logistics terms, measurement standard, technical standard, data transmission standard, logistics operation mode and management standard, and on the other hand, strengthen standardized organization and coordination work. Based on making in-depth research of national standards and industrial standards associated with logistics activities, it should comprehensively comb the existing standards, eliminate the standards that cannot meet the needs of logistics development and replace them with new standards. Revise and perfect standards that are not in accordance with actual needs and formulate relevant standards as soon as possible so as to make various related technical standards become coordinated and consistent and identical with the international standards.

Strengthen cultivation of logistics inter-disciplinary talents. Green logistics is a new thing. The government should offer great support and lead scientific work of green logistics. On the one hand, it has to actively support researches of basic theory and technology of green logistics. On the other hand, it has to cultivate inter-disciplinary talents in logistics management and application. As a science with strong applicability, an industry with strong practicalness and disciplinary with strong theoretical property, logistics can't do without combination of industry-university-research cooperation. Therefore, research has to be combined with teaching and apply the results of research to enterprises. Practical teaching has to be attached which is important in teaching, and cultivation of innovative talents should be strengthened.

Vigorously develop third-part logistics and realize joint distribution. Resource consumption, environmental pollution and traffic jam are major problems in regional (urban) logistics, whiles the causes for these problems are massive utilization of motor transport powered by gasoline and diesel oil. Excessive vehicles on the road are mainly resulted from excessive enterprises' self-supporting logistics in logistics activities such as close range transportation, distribution and custody. Self-supporting logistics leads to many vehicles drive in ballast on road, which has lowered efficiency of truck carrying, increased quantity of vehicles on road and increased the occurrence source for air pollution source and traffic accident. Therefore, it has to vigorously develop socialized and professional third-part logistics.

\section{Conclusions}

With the development of global economic integration, some traditional tariff and non-tariff barriers gradually fade, green barrier gradually rises and IS14000 becomes traffic permits for many enterprises getting access to international market. If China's logistics industry wants to take a place 
in the intense competition, green logistics will be the inevitable choice to win market and long-term development. Discussion on countermeasures for development of China's green logistics appears to be significant. It is a hope that this research can offer some realistic guiding significance.

\section{Acknowledgment}

This work was supported by Project on professional and characteristical construction of Jiangxi province 2010 (Civil Engineering) and Project on the planning and construction of disciplines in Jiangxi University of Technology (Structure Engineering)

\section{References}

[1] Sun Xiumei, Xin Guangqian. Study of Bottleneck and Countermeasure for Development of Green Logistics [J]. Chinese Business and Market, 2012, (10)

[2] Liu Dongyan, Hu Hao. Brief Analysis of Green Logistics of Chinese Enterprises [J]. Chuzhou Vocational Technology College Journal, 2013, (02)

[3] Cao Xiuli, Yan Huizhe, Chen Yuan. Perfection Measures for Development of China's Green Logistics [J]. Chinese Market, 2012, (Z2)

[4] Liang Yanjun, Zhang Huigang. Value and Development Countermeasures of Green Logistics [J] Investment Beijing, September 2010

[5] Qi Hongxiang. Analysis of Strategies for Developing Green Logistics [J]. Market Modernization, Vol. 19, 2011

[6] Wang Xuefeng. Analysis of Development of China's Green Logistics [J]. Market Modernization, 2012, (15)

[7] Lan Qingxin. Study of Development of Green Logistics System Based on Circular Economy [A]. The 2nd China's Green Commercial Development Summit Forum Proceedings [C], 2011

[8] Yan Wenzhong. Current Status and Countermeasures of Development of China's Green Logistics [J]. Science \& Technology Information, 2010 (1)

[9] Song Lijuan. Strategies for Enterprise Logistics Development Based on Concept of Circular Economy [J]. Chinese Market, 2010 (10)

[10] Paul R Murphy, Richard F Poist1Green Logistics strategies: An analysis of usage Pat-terns1Transportaion, Winter 2013

[11] TageSkjotett-Larsen. European Logistics beyond 2000. International Journal of Physical Distribution\&Logistics Management. 2012 